\title{
Program Director
}

National Cancer Institute

\section{Source}

National Cancer Institute. Program Director. NCI Thesaurus. Code C51849.

A professional who holds a leadership administrative, research, or academic position

within a scientific program. A program director is responsible for the overall direction in

the conduct of research; provision and coordination of training and education;

operations, staffing, and maintenance of research facilities; development of new

research activities; developing and maintaining relationships with other agencies,

programs, scientific centers and departments, as well as with communities. 